\title{
THREE FACES OF RECOMBINATION ACTIVATING GENE 1 (RAG1) MUTATIONS
}

\author{
Turkan Patiroglu ${ }^{1,2}$, Himmet Haluk AKaR ${ }^{1 *}$ \\ and MIRJAM VAN DER BURG ${ }^{3}$ \\ ${ }^{1}$ Erciyes University School of Medicine, Department of Pediatric Immunology, \\ Kayseri, Turkey \\ ${ }^{2}$ Erciyes University School of Medicine, Department of Pediatric Hematology and Oncology, \\ Kayseri, Turkey \\ ${ }^{3}$ Department of Erasmus MC, University Medical Center Rotterdam, Rotterdam, \\ the Netherlands
}

(Received: 16 October 2014; accepted: 8 August 2015)

Severe combined immune deficiency (SCID) is a group of genetic disorder associated with development of T- and/or B-lymphocytes. Recombination-activating genes (RAG1/2) play a critical role on VDJ recombination process that leads to the production of a broad T-cell receptor (TCR) and B-cell receptor (BCR) repertoire in the development of $\mathrm{T}$ and $\mathrm{B}$ cells. $R A G 1 / 2$ genes mutations result in various forms of primary immunodeficiency, ranging from classic SCID to Omenn syndrome (OS) to atypical SCID with such as granuloma formation and autoimmunity. Herein, we reported 4 patients with RAG1 deficiency: classic SCID was seen in two patients who presented with recurrent pneumonia and chronic diarrhoea, and failure to thrive. OS was observed in one patient who presented with chronic diarrhoea, skin rash, recurrent lower respiratory infections, and atypical SCID was seen in one patient who presented with Pyoderma gangrenosum (PG) and had novel RAG1 mutation.

Keywords: atypical SCID, classic SCID, Omenn syndrome, RAG1 mutation

\section{Introduction}

Recombination-activating genes $(R A G 1 / 2)$ effect on the VDJ (variable, diversity, and joining) recombination which leads to the generation of diverse antigen receptors [1]. A complete lack of RAG activity causes classic SCID manifestations with the absence of mature $\mathrm{T}$ and $\mathrm{B}$ cells, but the presence of natural killer (NK) cells (T-B-NK+SCID) [2]. On the other hand, the spectrum of dis-

*Corresponding author; E-mail: himmetakar@gmail.com 
ease has expanded to OS to atypical SCID with early onset autoimmunity, cytomegalovirus (CMV) infection with $\gamma \delta$ T-cell expansion, granuloma formation, and isolated $\mathrm{CD}^{+}$lymphopenia [3-8]. The different clinic spectrums of RAG deficiency are partially explained by different residual RAG activity. Although null mutations lead to classic SCID phenotype, hypomorphic mutations cause more variable clinic presentations [3,9]. Herein, we reported 4 patients with RAG1 deficiency with different clinical phenotypes from SCID to OS to atypical SCID.

\section{Cases}

\section{Patient \#1}

He was a 5-month-old boy. The patient was born after a normal pregnancy and delivery as the first child of second degree consanguineous parents. At the age of 20 days, he suffered from wheezing and hospitalized as bronchiolitis. His symptoms resolved with bronchodilators within 10 days. His respiratory symptoms repeated a few days later and he was interned again because of severe pneumonia for two months. Subsequently the patient was transferred to the Department Pediatric Immunology at the age of 3 months. Physical examination revealed failure to thrive, 3-4 cm hepatosplenomegaly below the costal margins, and bilateral crackles. Chest radiographs revealed pneumonia without thymus shadow. Laboratory findings at the time of admission were as follows; absolute neutrophil

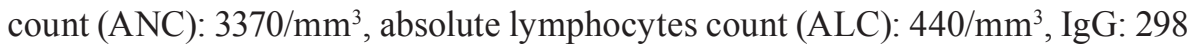
$\mathrm{mg} / \mathrm{dL}(345-1,236 \mathrm{mg} / \mathrm{dL}), \mathrm{IgM}: 16 \mathrm{mg} / \mathrm{dL}$ (41-173 mg/dL), and IgA: $6.1 \mathrm{mg} / \mathrm{dL}$ (14-159 mg/dL). Flow cytometric analysis of the lymphocyte subsets revealed:

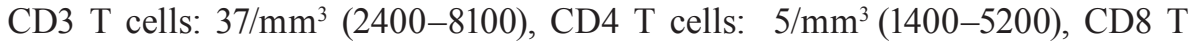
cells: $33 / \mathrm{mm}^{3}$ (600-300), CD19 B cells: $80 / \mathrm{mm}^{3}$ (300-1400), CD16/CD56 (NK) cells: $320 / \mathrm{mm}^{3}(200-1800)$. The clinical and laboratory findings were consistent with T-B-NK+ SCID. A homozygous missense mutation (c.1229G $>$ A, p.Arg$410 \mathrm{Gln}$ ) was detected in the RAG1 gene (Tables I and II). Haploidentical haematopoietic stem cell transplantation (HSCT) was performed from the mother. But he died from the progression of respiratory infection at +110 days after transplantation.

\section{Patient \#2}

A 7-month-old girl was transferred to the Department of Pediatric Immunology with complaints of recurrent thrush, chronic diarrhea, and anal fissure at the age of 2 months. She was born as second child of non-consanguineous par- 


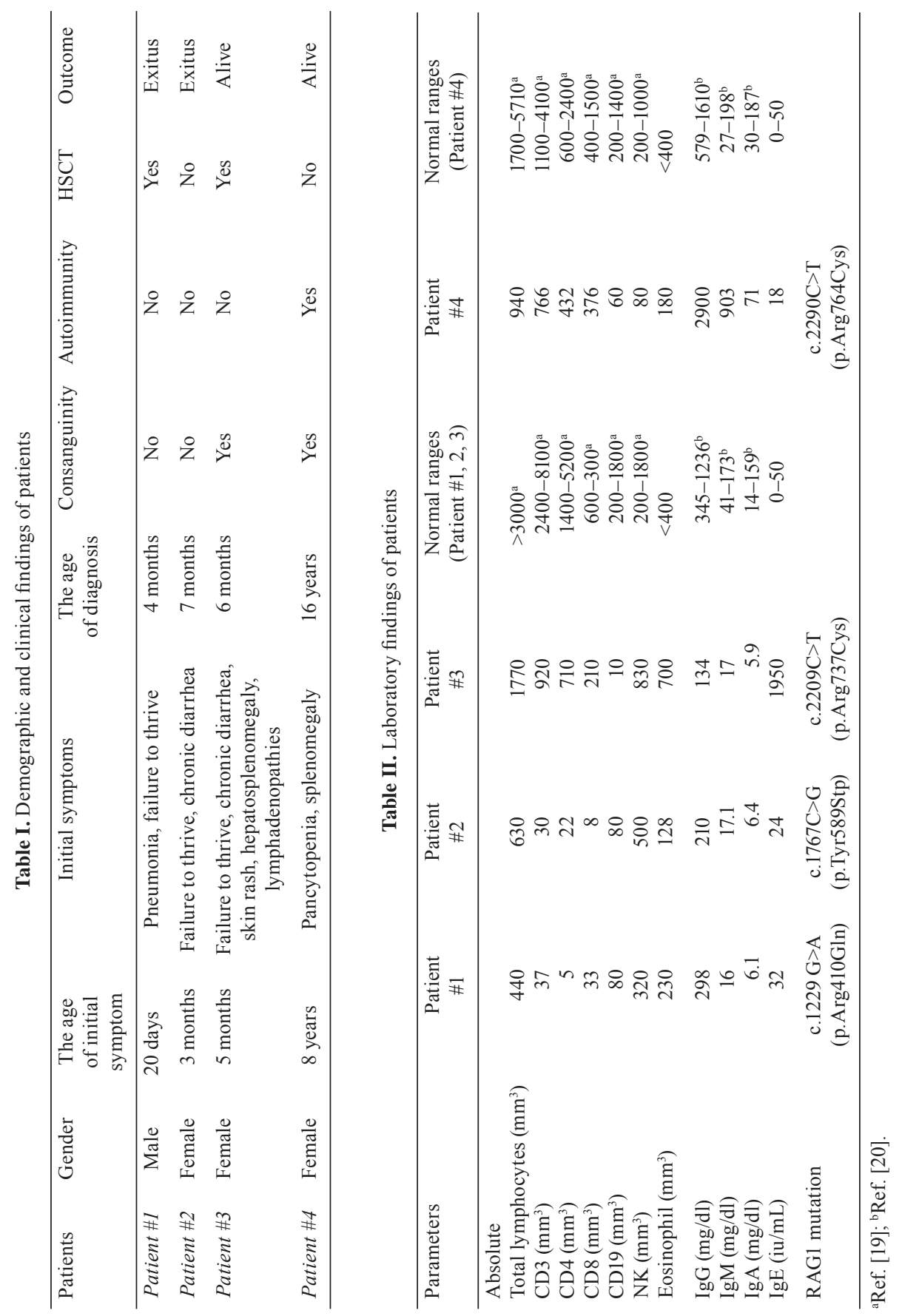


ents with weight of $3.2 \mathrm{~kg}$ at term. Physical examination revealed thrush and failure to thrive. No thymus shadow was observed on chest radiography. Laboratory investigations revealed; ALC: $630 / \mathrm{mm}^{3}$, IgG: $210 \mathrm{mg} / \mathrm{dL}(345-1236 \mathrm{mg} / \mathrm{dL})$, IgM: $17.1 \mathrm{mg} / \mathrm{dL}$ (41-173 mg/dL), IgA: $6.4 \mathrm{mg} / \mathrm{dL}$ (14-159 mg/dL), CD3 T cells: 30/mm $\mathrm{mm}^{3}$ (2400-8100), CD4 T cells: $22 / \mathrm{mm}^{3}$ (1400-5200), CD8 T cells: $8 / \mathrm{mm}^{3}$

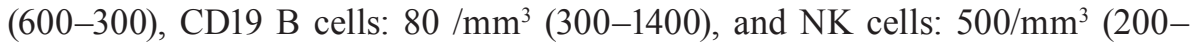
1800). Her condition was consistent with T-B-NK+ SCID. Diagnosis of SCID was confirmed by genetic analysis of the RAGl gene; a homozygous nonsense mutation (c.1767C $>$ G, p.Tyr589Stp) was detected (Tables I and II). Intravenous immunoglobulin (IVIG) replacement and antimicrobial prophylaxis with cotrimaxozole and itraconazole were initiated. HSCT was planned to the patient. Unfortunately she died due to pneumonia while unrelated donor screening at the age of 9 months.

\section{Patient \#3}

A 1.5-year-old girl was born as the second child of second degree consanguineous parents. She was referred to the Department of Pediatric Emergency with prolonged fever, cough, vomiting, chronic diarrhoea, and skin lesions at the age of 5 months. Physical examination revealed failure to thrive, 3-4 cm hepatosplenomegaly below the costal margins, axillary and inguinal multiple lymphadenopathies, bilateral crackles, and maculopapular rash on the trunk (Fig. 1a). Chest radiography revealed bilateral infiltrations which were consistent with severe pneumonia. Laboratory evaluation revealed ALC: 1770/ $\mathrm{mm}^{3}$, eosinophil: 19.5\% (770/mm 3), IgG: $134 \mathrm{mg} / \mathrm{dl}$ (345-1,236 mg/dl), IgM: $17 \mathrm{mg} / \mathrm{dl}$ (41-173 mg/dl), Ig: $6.3 \mathrm{mg} / \mathrm{dl}(14-159 \mathrm{mg} / \mathrm{dl}), \mathrm{IgE}: 1950 \mathrm{iu} / \mathrm{ml}(0-200 \mathrm{iu} / \mathrm{ml})$, CD3 T cells: $920 / \mathrm{mm}^{3}$ (2400-8100), CD4 T cells: $710 / \mathrm{mm}^{3}(1400-5200)$, CD8 T cells: $210 / \mathrm{mm}^{3}(600-$ 300), CD19 B cells: 10/mm³ (300-1400), and NK cells: $830 / \mathrm{mm}^{3}(200-1800)$. Her clinical and immunologic evaluation was consistent with a T-B-NK+SCID (OS). Flow cytometric analysis of the precursor B-cell compartment in bone marrow showed a complete block in precursor B cell differentiation. A RAG deficiency was suspected, and direct fluorescent sequencing of the $R A G 1$ gene revealed only a heterozygous mutation (c.2209C $>$ T, p.Arg737Cys). The second mutation in the RAG-1, RAG2, Artemis, and ADA genes were not found (Tables I and II). Haploidentical HSCT was performed at 1 year old from the father. The patient is well now (Fig. 1b).

\section{Patient \#4}

A 16-year-old girl was born as the first child of second consanguineous parents at term. In her first years of life she just had aphthous stomatitis, as some- 

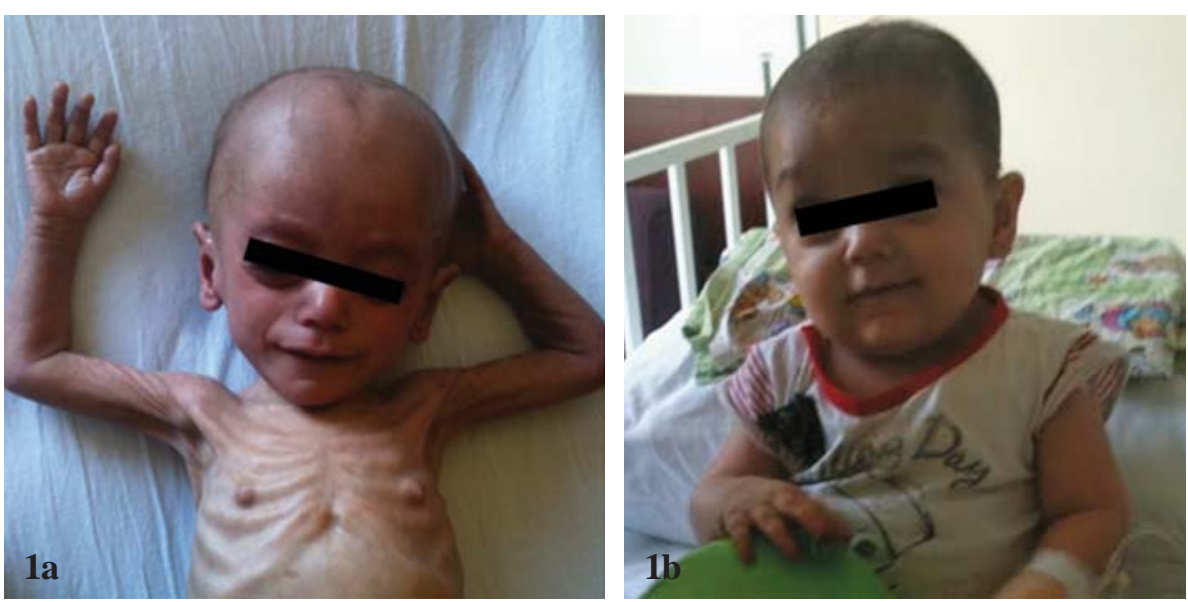

Figure 1. Omenn syndrome, (a) at the diagnosis time, (b) after the HSCT in patient \#3
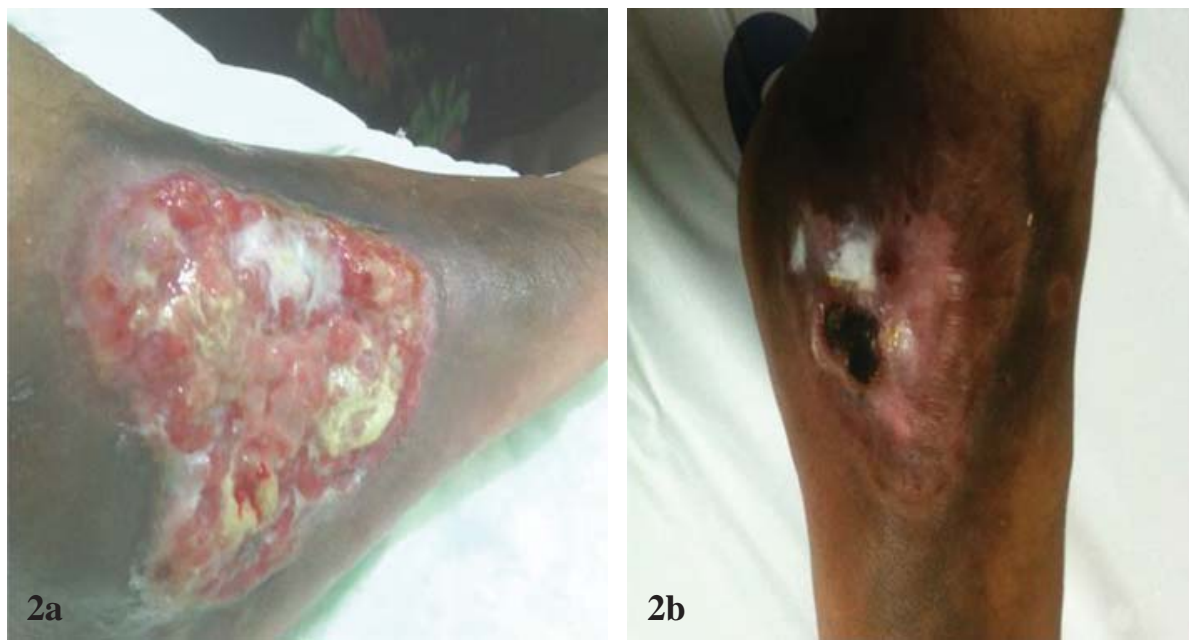

Figure 2. Pyoderma gangrenosum, (a) before the treatment, (b) after the treatment in patient \#4

times found in healthy children. At the age of 8 years, splenomegaly was observed and she was referred to the Department of Pediatric Immunology. Physical examination revealed splenomegaly. Immunologic evaluation revealed pancytopenia with ANC: $480 / \mathrm{mm}^{3}$, ALC: $940 / \mathrm{mm}^{3}$, hypergammaglobulinemia with IgG: 2900 mg/dL (527-1590), IgA: 903mg/dL (36-268), IgM: 71 mg/dL (30-220), IgE: $50 \mathrm{iu} / \mathrm{ml}(0-200)$, diminished number of lymphocytes subsets with CD3 cells: $766 / \mathrm{mm}^{3}$ (1000-4900), CD4 cells: $432 / \mathrm{mm}^{3}$ (500-2700), CD8 cells: $376 / \mathrm{mm}^{3}$ 


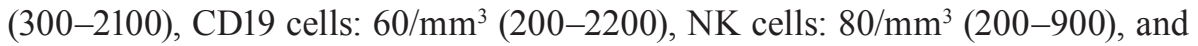
direct Coombs positive result. At first, because of splenomegaly, hypergammaglobulinemia, pancytopenia, positive double negative $\mathrm{T}$ cells $(5.5 \%)$ and positive autoantibodies the patient was thought to have autoimmune lymphoproliferative syndrome. At the age of 14 years, she experienced PG on her left ankle after an insect bite while on holiday (Fig. 2a). PG healed completely with different treatment over two years (Fig. 2b). Genetic analysis indicated that she has a novel homozygous mutation at cDNA position 2290 (c.2290C > T, p.Arg764Cys) in exon 2 of the $R A G 1$ gene (Tables I and II) [10].

\section{Discussion}

RAG1/2 genes are specifically expressed in immature T and B cells [11]. Mutations in the RAG1/2 genes can lead to null protein activity or hypomorphic protein activity depending on severity of the mutations. Although null mutations of RAG1/2 genes lead to classic T-B-NK+ SCID phenotype, hypomorphic mutations of these genes often result in OS and atypical SCID [12]. Mutations in RAG1/2 genes are responsible almost $10 \%$ of all SCID cases and usually these mutations result in classic T-B-NK+SCID. Mutations in the RAG1/2 genes account for approximately 70\% etiology of T-B-NK+SCID [13-14]. Two patients fulfilled clinical criteria of classic T-B-NK+SCID in the presented study. Haploidentical HSCT underwent one of them. Unfortunately, he died due to progression of respiratory infection at +110 days after transplantation. Second classic SCID patient also died at the age of 9 months while unrelated donor screening. Hypomorphic mutations in the RAG1/2 genes have been associated with different clinical and immunologic phenotypes that include OS and atypical SCID [15]. OS presents erythroderma, eosinophilia, lymphadenopathy, and increased serum $\mathrm{IgE}$ levels as presented in patient \#3. In medical literature, it has been reported two adult onset immunodeficiency caused by heterozygous mutations in RAG1 and adenosine deaminase deficiency (ADA) [16-17] as in patient \#3. Abraham et al. [16] reported a patient presented with chronic dermatitis, pruritus, and hyperkeratosis. In that patient, the clinical and immunologic examination showed eosinophilia, elevated IgE (747 kU/L), profound pan-T-cell lymphopenia results from heterozygous RAG1 mutation as in our patient \#3. Another patient with adult onset immunodeficiency caused by heterozygote ADA deficiency was reported by Shovlin et al. [17]. Additional to these articles reported by Abraham et al. [16] and Shovlin et al. [17], Pico-Knijnenburg et al. [18] reported three siblings who had recurrent infections, generalized rashes, malnutrition and chronic diarrhoea. In those siblings, there were extremely low T and B cells. Also, there was 
a complete block in precursor B cell differentiation in bone marrow as in the presented patient \#3. In those siblings, initially a heterozygous mutation in RAG1 gene was identified and subsequently second mutation was found with further investigations and they said that in the event of heterozygous mutations of RAG1 gene to detect other second defect further investigations are required [18]. In the presented patient \#3, as in those siblings reported by Pico-Knijnenburg et al. [18], only a heterozygous mutation in RAG1 gene. The second mutation in the RAG1, RAG2, Artemis, and ADA genes were not found with sequencing. Maybe we need further investigations to detect second mutation in the presented patient \#3 as said Pico-Knijnenburg et al. [18]. Atypical SCID result from RAG genes mutations shows varying numbers of $\mathrm{T}$ and $\mathrm{B}$ cells and varied clinic manifestations such combined immune deficiency with granuloma and/or autoimmunity, $\gamma \delta$ T lymphocytes expansion which is often associated with cytomegalovirus infection, idiopathic $\mathrm{CD}^{+} \mathrm{T}$ cell lymphopenia which presenting with extensive chickenpox and recurrent pneumonia, and early onset-autoimmunity [15]. The pleomorphic manifestations of RAG deficiency result from hypomorphic mutations are explained by residual RAG protein activity [7]. To date, at least 76 distinct mutations have been described RAG1 gene [15]. Sometimes epigenetic factors including compound genetic defects, environmental factors, and infections effect on the clinical manifestation of RAG1 gene mutations and may alter phenotypical characteristics of the mutations of RAG1 gene. This indicates that unknown factors may play a role on the clinical picture of RAG1 mutations [12]. In the presented study, patient \#4 presented with PG as atypical presentation. Also, in the presented patient \#4, a novel homozygous mutation was defined in exon 2 of RAG1 gene (c.2290C > T).

In conclusion, herein, four patients and three distinct clinical spectrums associated with RAG1 mutations were presented. The first and second patients had a typical classic T-B-NK+ SCID. The third patient was OS with the manifestations of erythroderma, lymphadenopathies, eosinophilia, and increased serum IgE levels. The fourth one was atypical SCID with high levels of immunoglobulins, low T cell, B cell and NK cell ratios, splenomegaly, PG, and autoimmunity. In the presented patients, the clinical and immunologic phenotypes were diverse as previously reported RAG1 mutations. In addition to classic SCID presentation in patients with atypical manifestation, as in the presented patient \#4, it is important to keep in mind the mutations of RAG1 genes.

\section{Conflict of Interest}

The authors declare that they have no conflict of interest. 


\section{References}

1. Gellert, M.: V(D)J recombination: RAG proteins, repair factors, and regulation. Annu Rev Biochem 71, 101-132 (2002).

2. Schwarz, K., Gauss, G. H., Ludwig, L., Pannicke, U., Li, Z., Lindner, D., Friedrich, W., Seger, R. A., Hansen-Hagge, T. E., Desiderio, S., Lieber, M. R., Bartram, C. R.: RAG mutations in human B cell-negative SCID. Science 274, 97-99 (1996).

3. Villa, A., Santagata, S., Bozzi, F., Giliani, S., Frattini, A., Imberti, L., Gatta, L. B., Ochs, H. D., Schwarz, K., Notarangelo, L. D., Vezzoni, P., Spanopoulou, E.: Partial V(D)J recombination activity leads to Omenn syndrome. Cell 93, 885-896 (1998).

4. Henderson, L. A., Frugoni, F., Hopkins, G., de Boer, H., Pai, S. Y., Lee, Y. N., Walter, J. E., Hazen, M. M., Notarangelo, L. D.: Expanding the spectrum of recombination-activating gene 1 deficiency: A family with early-onset autoimmunity. J Allergy Clin Immunol 132, 969-971 (2013).

5. Schuetz, C., Huck, K., Gudowius, S., Megahed, M., Feyen, O., Hubner, B., Schneider, D. T., Manfras, B., Pannicke, U., Willemze, R., Knüchel, R., Göbel, U., Schulz, A., Borkhardt, A., Friedrich, W., Schwarz, K., Niehues, T.: An immunodeficiency disease with RAG mutations and granulomas. N Engl J Med 358, 2030-2038 (2008).

6. de Villartay, J. P., Lim, A., Al-Mousa, H., Dupont, S., Déchanet-Merville, J., CoumauGatbois, E., Gougeon, M. L., Lemainque, A., Eidenschenk, C., Jouanguy, E., Abel, L., Casanova, J. L., Fischer, A., Le Deist, F.: A novel immunodeficiency associated with hypomorphic RAG1 mutations and CMV infection. J Clin Invest 115, 3291-3299 (2005).

7. Ehl, S., Schwarz, K., Enders, A., Duffner, U., Pannicke, U., Kühr, J., Mascart, F., SchmittGraeff, A., Niemeyer, C., Fisch, P.: A variant of SCID with specific immune responses and predominance of gamma delta T cells. J Clin Invest 115, 3140-3148 (2005).

8. Kuijpers, T. W., Ijspeert, H., van Leeuwen, E. M., Jansen, M. H., Hazenberg, M. D., Weijer, K. C., van Lier, R. A., van der Burg, M.: Idiopathic CD41 T lymphopenia without autoimmunity or granulomatous disease in the slipstream of RAG mutations. Blood 117, 5892-5896, (2011).

9. Villa, A., Sobacchi, C., Notarangelo, L. D., Bozzi, F., Abinun, M., Abrahamsen, T. G., Arkwright, P. D., Baniyash, M., Brooks, E. G., Conley, M. E., Cortes, P., Duse, M., Fasth, A., Filipovich, A. M., Infante, A. J., Jones, A., Mazzolari, E., Muller, S. M., Pasic, S., Rechavi, G., Sacco, M. G., Santagata, S., Schroeder, M. L., Seger, R., Strina, D., Ugazio, A., Väliaho, J., Vihinen, M., Vogler, L. B., Ochs, H., Vezzoni, P., Friedrich, W., Schwarz, K.: V(D)J recombination defects in lymphocytes due to RAG mutations: Severe immunodeficiency with a spectrum of clinical presentations. Blood 97, 81-88 (2001).

10. Patiroglu, T., Akar, H. H., Gilmour, K., Ozdemir, M. A., Bibi, S., Henriquez, F., Burns, S. O., Unal, E.: Atypical severe combined immunodeficiency caused by a novel homozygous mutation in Rag1 gene in a girl who presented with pyoderma gangrenosum: A case report and literature review. J Clin Immunol 34, 792-795 (2014).

11. Schatz, D. G.: V(D)J recombination. Immunol Rev 200, 5-11 (2004).

12. Kutukculer, N., Gulez, N., Karaca, N. E., Aksu, G., Berdeli, A.: Novel mutations and diverse clinical phenotypes in recombinase-activating gene 1 deficiency. Ital J Pediatr 38, 1-7 (2012).

13. Fischer, A.: Have we seen the last variant of severe combined immunodeficiency? N Engl J Med 349, 1789-1792 (2003). 
14. Karaca, N. E., Aksu, G., Genel, F., Gulez, N., Can, S., Aydinok, Y., Aksoylar, S., Karaca, E., Altuglu, I., Kutukculer, N.: Diverse phenotypic and genotypic presentation of RAG1 mutations in two cases with SCID. Clin Exp Med 9, 339-342 (2009).

15. Lee, Y. N., Frugoni, F., Dobbs, K., Walter, J. E., Giliani, S., Gennery, A. R., Al-Herz, W., Haddad, E., Le Deist, F., Bleesing, J. H., Henderson, L. A., Pai, S. Y., Nelson, R. P., ElGhoneimy, D. H., El-Feky, R. A., Reda, S. M., Hossny, E., Soler-Palacin, P., Fuleihan, R. L., Patel, N. C., Massaad, M. J., Geha, R. S., Puck, J. M., Palma, P., Cancrini, C., Chen, K., Vihinen, M., Alt, F. W., Notarangelo, L. D.: A systematic analysis of recombination activity and genotype-phenotype correlation in human recombination-activating gene 1 deficiency. J Allergy Clin Immunol 133, 1099-1108 (2014).

16. Abraham, R. S., Recher, M., Giliani, S., Walter, J. E., Lee, Y. N., Frugoni, F., Maddox, D. E., Kirmani, S., Notarangelo, L. D.: Adult-onset manifestation of idiopathic T-cell lymphopenia due to a heterozygous RAG1 mutation. J Allergy Clin Immunol 131, 1431-1433 (2013).

17. Shovlin, C. L., Simmonds, H. A., Fairbanks, L. D., Deacock, S. J., Hughes, J. M., Lechler, R. I., Webster, A. D., Sun, X. M., Webb, J. C., Soutar, A. K.: Adult onset immunodeficiency caused by inherited adenosine deaminase deficiency. J Immunol 153, 2331-2339 (1994).

18. Pico-Knijnenburg, I., Jspeert, H., Pac, M., Turul, T., Hartwig, N., Sanders, E.: Can heterozygous RAG1 mutations be disease-causing? XIVth Meeting of the European Society for Immunodeficiencies (ESID) in Istanbul. Abstract Book, 203-204 (2010).

19. Ikinciogullari, A., Kendirli, T., Dogu, F., Eğin, Y., Reisli, I., Cin, S., Babacan, E.: Peripheral blood lymphocyte subsets in healthy Turkish children. Turk J Pediatr 46, 125-130 (2004).

20. Aksu, G., Genel, F., Koturoglu, G., Kurugöl, Z., Kütükçüler, N.: Serum immunoglobulin (IgG, IgM, IgA) and IgG subclass concentrations in healthy children: A study using nephelometric technique. Turk J Pediatr 48, 19-24 (2006). 